\title{
CIÊNCIA DO SISTEMA TERRA E O ENTENDIMENTO DA "MÁQUINA" PLANETÁRIA EM QUE VIVEMOS
}

\author{
Celso D. R. Carneiro, Pedro W. Gonçalves, Oscar B. M. Negrão \& Carlos A. L. Cunha (*)
}

\begin{abstract}
The disciplines Earth System Science I and II compose the core of the Earth Sciences undergraduate course, at the State University of Campinas. The biggest challenge is to combine the contents of both geology and geography to enable the students to understand Earth. Because it, these disciplines should approach the nature of knowledge and the methods of the two sciences in order to integrate knowledge about environmental interactions. Would this be possible by means of such an introductory course? Our approach has favoured a treatment of the relationship among different spheres: geosphere, hidrosphere, atmosphere, biosphere and the human sphere. The ossified forms registered in the lithosphere are the unique way for us to know events of the geologic past. To understand present cycles and processes we also depend on ossified forms in order to recover the history and evolution of the environment. Plate Tectonics starts the initial classes aiming to emphasize the logic of studying the Earth's past, as it embraces long to medium time-span cycles and processes. The present and short-time-span phenomena are considered natural events with relations of mankind and all other terrestrial spheres. Field trips are essential to observe these natural and human-related processes. Supported on the idea of the technical-scientific-informational medium, our point-of-view addresses to environmental questions and hazard events. As well as the teachers encourage the students to conquest their own apprenticeship they play an active role to organize these situations.
\end{abstract}

\section{INTRODUÇ̃̃̃O}

Geografia e Geologia são carreiras abertas aos estudantes do programa de Ciências da Terra do IG-Unicamp ${ }^{1}$. As disciplinas Ciência do Sistema Terra I e II são oferecidas em semestres sucessivos do primeiro ano (Carneiro et al. 1998, 2000) e compõem o núcleo comum das duas carreiras profissionais, ou seja, são disciplinas básicas para estudantes dos dois cursos, oferecidas desde 1998. A proposta dessa graduação (no caso de geologia, é o primeiro curso criado desde 1976) é conduzir os alunos a relacionar os estudos do sistema Terra e os do sistema mundo (Quadro 1). Neste texto expomos os pressupostos de conteúdo que amparam o trabalho educacional iniciado no IG-Unicamp; discutimos ainda em que medida essas disciplinas poderão exercer papel estruturador de currículos em cursos de graduação na área de Ciências da Terra, expressão aqui entendida como sinônimo de Geociências.

É possível articular os conteúdos de geologia aos de geografia humana em uma disciplina introdutória na universidade? Como isso é possível? Uma tal abordagem que venha a tratar a Terra como um sistema interativo (King, 1990) ajudaria a capacitar o aluno a compreender o planeta?

Ao tentar responder a tais perguntas defendemos a idéia de que, por mais distintos que pareçam ser os conceitos da geologia e da geografia, é possível relacioná-los e isso contribui para formar estudantes que, a um só tempo, compreendam os processos que ocorrem no planeta e na sociedade. Para que isso fôsse possível foi necessário criar uma equipe interdisciplinar reunindo profissionais de diferentes áreas, possuidores de variados objetivos, experiência de pesquisa e indagações científicas. Admitimos que a união da equipe dependa da crença na possibilidade de capacitar competentemente os estudantes à medida que se pode avançar na pesquisa.

Duas vertentes principais convergem para estruturar esse tipo de estudo. Em primeiro lugar, o aprofundamento da crise ambiental põe em risco a preservação da espécie humana e seu atual patamar de civilização. Isso exige tratamento interdisciplinar dos problemas e, ao mesmo tempo, aprofundamento dos estudos em cada área de conhecimento. Em segundo, existe hoje, mais claramente que nunca, a possibilidade de olhar o planeta em sua totalidade por meio dos modernos recursos técnicos de levantamento e comunicação de dados. Vivemos a "era da observação em todas as escalas" (Fyfe, 1997). As duas questões revelam com toda crueza a necessidade de uma atitude ética frente à sociedade e à natureza, atitude esta que precisa contemplar os direitos e as potencialidades do homem para interagir com a natureza.

${ }^{1}$ Instituto de Geociências da Universidade Estadual de Campinas

$\left({ }^{*}\right)$ Profs. do Instituto de Geociências, Universidade Estadual de Campinas (Unicamp),

Caixa Postal 6152, 13083-970, Campinas, SP, Brasil. cedrec@ige.unicamp.br 


\section{CIÊNCIADOSISTEMA TERRA:CARACTERÍSTI- CAS DO ENSINO}

Cuello Gijón (1988) indicou algumas possibilidades para se desenvolver um programa interdisciplinar baseado em geociências. Domingo \& Sequeiros (1998) assinalam que o conhecimento das ciências da Terra contribui para a educação integral de todas as pessoas. Carneiro et al. (1998) defende que criatividade é essencial para os profissionais, bem como para o ensino, além de ser uma habilidade para compreender os processos naturais. Além disso, apesar das exigências de informação para se compreender fatos relativos às geociências, os profissionais sentem-se limitados para tratar de problemas complexos e multidisciplinares. Para interpretar as características naturais, seus eventos e ciclos, um pesquisador deve exercitar procedimentos típicos de ciências e não-históricas (pensamento analógico, indutivo, dedutivo e multifatorial).

Os profissionais devem conceber e analisar sistemas, produtos e processos, adotando modelos para gerar e expandir as aplicações das geociências; precisam ser capazes de traduzir processos e características em mapas temáticos. Necessitam, ainda, dominar informações importantes por meios informacionais. Entre as atividades dos profissionais de geociências acha-se a elaboração de mapas geológicos, geoquímicos e geofísicos para levantamento local e regional, planejamento de uso do solo, avaliações de recursos minerais, energéticos e hidrológicos. Entretanto, comunicar esses dados a outros profissionais, incluindo aqueles que não possuem formação específica, constitui desafio a ser enfrentado.

Interdisciplinaridade implica capacidade para enfrentar problemas complexos considerando uma variedade de parâmetros e processos. Inclui quesitos de aspectos administrativos, legais, sócio-econômicos e culturais relativos às relações de homem e ambiente. Os estudantes, portanto, necessitam conhecer diversas linguagens (outras ciências, culturas, políticas etc.) para discutir e explicar seus pontos de vista a outros e compreender os elementos sociais e legais. No contexto social e cultural, um programa coordenado de geografia e geologia necessita ser enfatizado: trata-se de excelente oportunidade para promover a comunicação entre os profissionais das ciências naturais e sociais.

Os conteúdos tratados (Quadro 1) buscam, nessa abordagem, atingir certos objetivos: (1) ressaltar o papel central da pesquisa para se conhecer as múltiplas interações do ambiente terrestre; (2) formar uma idéia articulada - ao mesmo tempo indagadora e questionadora - da ciência; (3) aplicar um foco interdisciplinar para tratar os efeitos das atividades humanas e sociais na superfície terrestre. A equipe estruturou temas que contemplem: (1) a perspectiva de trabalho (a epistemologia) do estudo geológico da Terra, (2) o estudo de processos globais, sejam eles naturais, artificiais ou articuladores da natureza e sociedade, e (3) a articulação desses estudos com definições típicas da geografia humana.

\author{
Ciência do Sistema Terra I \\ 1 Princípios dos estudos da Terra \\ 2 Geosfera \\ 3 Interação das esferas fluidas \\ 4 Biosfera e a interação com as outras esferas \\ 5 Introdução ao estudo do sistema mundo \\ Ciência do Sistema Terra II \\ 6 Geosfera e do sistema mundo \\ 7 As memórias do mundo \\ 8 Sistema mundo como trabalho e como norma \\ 9 As desigualdades do sistema mundo: regiões \\ planetárias \\ Quadro 1: Unidades conceituais principais. \\ Chart 1: Main concept units.
}

Tais nexos entre tecnosfera e ecosfera exigem que a Terra seja tratada como um todo. O aperfeiçoamento do corpo de conhecimento a ser desenvolvido junto aos alunos, ou seja, as unidades conceituais e seus possíveis vínculos, conduzem à compreensão do planeta desde abordagens distintas, embora inter-relacionadas. Dentre as opções de desenvolvimento da disciplina, o entendimento dos ciclos de formação de recursos naturais no tempo geológico acha-se separado da ocupação do espaço superficial e do desenvolvimento tecnológico. Distingue-se ainda das formas de domínio do homem sobre o mundo natural. Contudo, estabelecem-se diferentes vínculos entre esses três grandes campos, quando tentamos compreender o planeta simultaneamente em sua globalidade e nas suas especificidades locais e regionais. Desse modo, buscamos explicitar assuntos centrais para se entender o planeta. Pelo lado da Geologia, a teoria da Tectônica de Placas permite estudar o conjunto dos processos terrestres e as interações temporais das diferentes esferas. Pelo da Geografia, o meio técnico-científicoinformacional habilita a compreender os processos de exclusão social. Pode-se, assim, revelar a natureza das duas ciências.

\section{A base epistemológica das atividades propostas}

Os estudantes são conduzidos ao longo de uma linha estreita que une "sistema terra" e "sistema mundo". Para alcançar tal pretensão valorizam-se os modos de trabalho das duas áreas para as quais os alunos estão sendo preparados (geografia e geologia). O fazer das ciências da Terra representa, sobretudo, os traços metodológicos básicos, os processos envolvidos, os conceitos e definições dos dois campos. Tal exposição é claramente separada no tempo, buscando revelar uma imagem evolutiva do sistema natural e do domínio humano sobre este.

Uma certa idéia de progresso e ciclicidade acha-se no núcleo da conexão, que valoriza certas noções e habilidades, tais como: operar com diferentes escalas de tempo e espaço, classificar e diferenciar fatos e processos, operar com analogia para reconstituir fatos e eventos, operar com pensamento multifatorial para analisar fenômenos naturais e sociais. 
Há uma questão persistente no trabalho da disciplina: os diferentes enfoques que podem ser adotados para estudar o planeta mesmo dentro do campo científico. Os diversos modos de olhar a Terra são válidos e devem ser compreendidos nas suas potencialidades cognitivas e em seus limites. O cotidiano de trabalho vem revelando que é importante destacar o papel dos diversos campos de estudo, tanto para formar uma perspectiva profissional mais objetiva, como para conduzir os estudantes à opção profissional.

\section{Abordagem geológica}

Certo número de traços temáticos assinala a abordagem que poderíamos denominar geológica em Ciência do Sistema Terra.

Em primeiro lugar, é preciso notar a visão corrente dos profissionais da área de geociências em relação à Ciência do Sistema Terra. Em termos algo simplificados, tal perspectiva encontra amparo nos estudos que valorizam as questões ambientais e os problemas de risco natural nos estudos terrestres. A questão ambiental acha-se na própria raiz da Geologia como ciência, pois, conforme acentua Loon (1999), ela "não teria qualquer interesse científico se a Terra não tivesse sido afetada no passado por mudanças ambientais". Entretanto, para compreender como se alcançou tal abordagem é necessário trazer alguns elementos históricos que marcaram o estudo da Terra nas últimas décadas.

A organização sistêmica para o estudo histórico do planeta Terra tem certos traços históricos relativos ao período em que a geologia diferenciou-se da história natural e foi constituindo-se como campo epistêmico dedicado à história da Terra, das rochas e dos minerais e admitiu um enfoque associado à descoberta de jazidas minerais metálicas e energéticas. O conhecimento sobre a Terra não foi o resultado da reunião de estudos particulares e de aspectos específicos mas, ao contrário, já no ponto de partida apoiou-se em uma idéia integrada do planeta e das rochas que o compõem. O naturalista James Hutton, em seus famosos estudos sobre o planeta, reúne de modo coerente e complementar seus levantamentos de campo, descrições de locais e estratos particulares com as explicações gerais sobre origem e história de toda a Terra (Hutton, 1899; Gonçalves, 1997). Na verdade, de certo modo, esse início dos estudos geológicos, no final do século XVIII, atingiu abordagem e enfoque que não descuidaram das preocupações práticas entre o conhecimento da científico da natureza e suas possíveis aplicações para aumentar o rendimento da agricultura e mineração(Jones² , 1986; Dean, 1992). Fugiria demasiadamente deste espaço tratar de demonstrações dessas assertivas sobre os primórdios da ciência geológica; dentre outros, poderíamos recomendar a consultaa Gonçalves(1997).

Frodeman (1995) assinala questões nucleares para compreender como a geologia trabalha ao enfatizar o caráter interpretativo, hipotético e narrativo dessa ciência.
$\mathrm{O}$ primeiro aspecto acha-se vinculado à necessidade de decodificar sinais e revela a necessidade da linguagem visual e do pensamento analógico. $\mathrm{O}$ segundo e terceiro encontram-se articulados com o caráter histórico da geologia. Tal tratamento conduz a decorrências complexas que devem ser reveladas (pois muitas vezes ficaram encobertas) porque a geologia foi analisada somente desde um ponto de vista analítico - o qual opera um reducionismo incapaz de perceber traços mais significativos desse conhecimento sintético sobre a natureza (p. 965).

Um momento fundamental para pensarmos o ensino de geologia é quando, de certo modo, foi cunhada a expressão geociências. Na perspectiva aqui tratada, do ensino e da caracterização de uma abordagem que veio a ser denominada ciência do sistema Terra, é particularmente relevante o lançamento da obra Investigating the Earth (ESCP, 1975, 1976), a partir de projeto elaborado nos EUA pelo Earth Science Curriculum Project, ESCP, 1967). Seja do ponto de vista de sua importância como um dos projetos de inovação do ensino de ciências norte-americano, da década de 1960, ou pela influência editorial (materializada, até hoje, naquele país, por meio de seus kits didáticos) trata-se de uma inflexão no ensino dos aspectos naturais vinculados ao planeta. Mas, em termos conceituais e metodológicos, quais mudanças efetivas esse livro-curso provocou?

Simpson (1970, original de 1962) expõe os traços cruciais que estruturam o conhecimento clássico dos estudos da Terra. Enfatiza que a geologia é, ao mesmo tempo, uma ciência histórica e física. Neste caso ela estuda processos como o fazem as demais ciências naturais e experimentais (principalmente física e química), pois busca regularidades e leis gerais válidas em qualquer lugar, a qualquer tempo, para explicar processos físicos e repetitíveis como, p. ex.: erosão. Como ciência física, a geologia seria fundamentalmente indutiva. No outro caso, como ciência histórica, a geologia estuda o particular e o contingente, ou seja, a seqüência específica de processos singulares que conformaram uma região, $p$. ex.: a evolução do Grand Canyon. Na última situação, a geologia necessita de um método que lhe é próprio: o uniformitarismo metodológico. Tal método, conhecido como Atualismo (Carneiro et al. 1994), acha-se caracterizado pelo entendimento de processos modernos que possam aclarar aqueles ocorridos no passado.

Essas marcas aparentemente teóricas e desprovidas de nexos com as pesquisas científicas acham-se exemplificadas nos compêndios clássicos da geologia. É bem conhecido, no Brasil, o texto elaborado por Arthur Holmes (Principles of Physical Geology, primeira edição de 1944; Holmes \& Holmes, terceira edição de 1978) que organiza o conteúdo geológico de forma similar à revelada, anos depois, por Simpson (1970). Mesmo o texto de Tarbuck \& Lutgens (1996), embora tenha aparência moderna, corresponde nos traços fundamentais à mesma abordagem. Amaral (1981) analisa e descreve quarenta livros-textos para

\footnotetext{
${ }^{2}$ Os principais trabalhos de Jean Jones, sobre o naturalista britânico James Hutton, foram publicados nos Annals of Science: James Hutton and the Forth and Clyde Canal (v. 39, p. 255-263, 1982); James Hutton: exploration and oceanography (v. 40, p. 81-94, 1983); The geological collection of James Hutton (v. 41, p. 223-244, 1984); James Hutton's agricultural research and his life as a farmer (v. 42, p. 573-601, 1985).
} 
ensino de geologia introdutória e demonstra que significativa parcela dos mesmos encontra-se dentro dessa perspectiva em termos de seu conteúdo e enfoque. Todos conhecemos o livro de geologia introdutória mais adotado nas universidades brasileiras (Leinz \& Amaral, Geologia geral, primeira edição de 1962, décima-primeira em 1989) que acompanha a abordagem da obra de Holmes.

Se pudéssemos tentativamente enumerar certo conjunto de caracteres dessa abordagem científica, que foram veiculados pelo processo educativo, podemos dizer que se trata de um estudo descritivo da crosta terrestre, organizado segundo o predomínio relativo de fontes de energia (processos endógenos e exógenos, respectivamente dominados pela energia interna da Terra e pelo Sol), valorizando principalmente os processos continentais (geologia regional) e tratando secundariamente os campos de aplicação da geologia. À medida que a tectônica de placas consolidou-se como teoria e a crise ambiental foi adquirindo destaque, estudos sobre a litosfera, crosta oceânica, recursos energéticos e geologia de engenharia foram recebendo atenção dentro dessas obras. Talvez o elemento mais marcante, pelo alcance pedagógico dessas obras, é o de veicular uma idéia de ciência que estuda aspectos e fatos singulares por meio de um viés fortemente empírico.

Quase todas essas marcas da geologia da década de 1950 seriam alteradas, em maior ou menor profundidade, pela abordagem do ESCP e, talvez, em virtude disso tenham tornado tão significativo o termo geociências. O ponto marcante das geociências foi ampliar o campo de estudos: além da crosta terrestre, o ensino passou a incluir a atmosfera, hidrosfera e espaço estelar, cada um deles merecendo um estudo específico de seus processos. O ESCP avançou, ainda, no problema do método: supôs que todas as ciências poderiam ser integradas pelo método indutivo e isso implicou a adoção de certos temas centrais: previsão, universalidade da transformação e perspectiva sistêmica; implicitamente, admitiu que o uniformitarismo seria diferente da indução. Ora, isso conduziu a uma abordagem integrada de todos os processos terrestres por meio de sucessivas inter-relações dos eventos que ocorrem em cada uma das esferas materiais do planeta (atmosfera, hidrosfera, crosta terrestre, manto e núcleo, espaço estelar). Tal esforço para englobar todas as transformações terrestres é finalmente atingido no estudo do passado da Terra e na evolução astrofísica do universo.

As diferenças com as formas clássicas de conhecimento geológico são marcantes e, de fato, nas décadas seguintes, de um lado, um número maior de obras adotou títulos que fornecem uma imagem mais integrada dos estudos da Terra, de outro, os livros com títulos tradicionais, em alguma medida, adaptaram seus tópicos e abrangência para incluir estudos sobre atmosfera, hidrosfera e espaço estelar. Podese afirmar que se encontra nesse movimento o embrião de uma "Ciência do Sistema Terra".
Assinalamos, ainda, que tal processo foi acompanhado de profundas reformulações no modo como os geólogos viam sua ciência. No final da década de 1960 a teoria da tectônica de placas foi tomando lugar da teoria geossinclinal, avançou pari-passu com as novas técnicas de pesquisa (utilização do magnetômetro, avanços técnicos do sonar, detalhamento dos estudos sísmicos e informes provindos do espaço exterior) e tornou-se a teoria hegemônica que fornece um tratamento global aos processos terrestres.

Contudo, antes de alcançar esse momento de inflexão da pesquisa e ensino, Potapova (1968, original de 1963) alertava para a crise da ciência geológica: tratava-se, segundo seu ponto de vista, de certa confusão metodológica: geólogos, geoquímicos e geofísicos tomaram a crosta terrestre como sendo o objeto de estudo da geologia. A autora prega que o problema mais geral dessa área científica acha-se voltado para a história da Terra e as múltiplas inter-relações temporais das esferas materiais do planeta (incluindo, dentre estas, a esfera social). A crosta terrestre, dessa forma, deveria ser tomada apenas como objeto de investigação mais imediato, ou seja, trata-se do local privilegiado para fazer observações, formular e testar hipóteses e teorias geológicas.

Ora, essa atitude frente ao planeta conduz a um retorno mais orgânico de estudo das geociências na medida em que hierarquiza e organiza as pesquisas dos diversos campos sob o enfoque histórico. Tal ordem encontra-se ligada à idéia de processo histórico-geológico, ou seja, este é o objeto de estudo da geologia: cada pesquisa particular contribui para construir a noção geral perseguida por esse campo da ciência.

Potapova (1968) avança, ainda, o debate na questão do uniformitarismo: visto como um caso particular do método histórico-comparativo (e marcando, dessa maneira, o afastamento das interpretações de que o uniformitarismo corresponderia apenas a uma versão do método indutivo) ${ }^{3}$. O confronto com as fórmulas expostas por Simpson (1970) é estratégico: Potapova (1968) é clara quanto ao caráter histórico da geologia, mas, e os estudos físicos imaginados por Simpson como geológicos? Trata-se de pesquisas realizadas pelas diferentes ciências e técnicas que estudam os processos do presente, assinala a autora soviética. Os resultados e informes destas investigações servem para interpretar os fenômenos ocorridos no passado e, somente aí, tornam-se problemas geológicos.

Embora tal abordagem seja mais holística (Carneiro et al. 1994) do que a preconizada pelas geociências, duas questões saltam aos olhos:

1) a visão equaciona estudos particulares e os articula em um conjunto orgânico da ciência histórica, mas não teve suficiente aceitação e permaneceu restrita ao debate de grupos dedicados a temas epistemológicos;

2) o silêncio da autora, crucial, diante dos campos de aplicação da geologia. 
O quadro conceitual das ciências geológicas, esboçado acima, não se alterou de modo significativo em termos do ensino tradicional até a década de 1990. Nesse largo período de trinta anos, as preocupações ambientais cresceram e a idéia de educação ambiental dispersou-se em diversificados campos das ciências. Isso gerou certos estudos que reuniram as ciências ambientais e elementos clássicos da geologia para tratar dos sistemas terrestres. Alguns utilizam ainda hoje a expressão geologia ambiental como se fosse possível existir uma geologia não-ambiental.

O parágrafo acima, embora demasiadamente simplificado, destaca o tipo de desafio que foi sendo posto para o ensino das ciências geológicas. A crise ambiental, por um lado, os recursos técnicos e especialmente os dados obtidos por sensores remotos, por outro, conduziram aos estudos chamados de ciência do sistema Terra o qual, em largos traços, conecta o enfoque que já estava presente nas geociências - a abordagem sistêmica - aos campos de aplicação do conhecimento geológico (riscos, impactos etc.).

\section{GEOSFERA:UMEXEMPLO}

O enfoque educativo da ciência do sistema Terra nada mais é do que um esforço de tratar o planeta como uma entidade única que reúne a história geológica interagindo com as transformações sociais e isso implica discutir, dentre inúmeros outros aspectos, recursos naturais e impactos ambientais. Mesmo essa visão naturalizada dos processos terrestres não se constitui plenamente. Os esforços realizados justapõem estudos de cada uma das esferas materiais terrestres: atmosfera, hidrosfera, litosfera, espaço estelar, manto e núcleo e, finalmente, biosfera. Além disso, os campos de aplicação permanecem sob o enfoque tradicional, primeiro, das potencialidades e limites dos recursos naturais (o que inclui aspectos demográficos, econômicos, sociais, políticos e culturais) e, segundo, do tratamento dicotômico dos impactos, ora vistos como impactos sobre o ambiente (incorporando os acidentes tecnológicos) e, em outro instante, tomados como impactos de uma transformação natural sobre a sociedade (o que inclui os acidentes naturais). $\mathrm{O}$ texto de Mackenzie e Mackenzie (1995) exemplifica tal abordagem: os autores valorizam os estudos biológicos atribuindo a estes importância equivalente ao de outras esferas materiais terrestres (atmosfera, hidrosfera, litosfera etc.) e, à parte, segue um estudo de diferentes impactos ambientais.

O seguinte exemplo ilustra como o curso relaciona diferentes conceitos. Tomamos a unidade Geosfera porque ela reúne uma variedade de técnicas, estratégias e articulações de conteúdo que exibem o tratamento adotado pela perspectiva da ciência do sistema Terra.

Estudar a geosfera é compreender os processos terrestres tomados como um todo e em suas partes conforme eles foram registrados na organização, disposição e composição das esferas rochosas. Isso implica compreender relações das esferas rochosas e as demais esferas do planeta (tecnosfera, biosfera, atmosfera e hidrosfera). Além disso, a abordagem geológica conduz ao exame da história da Terra tomada a partir dos processos refletidos no registro geológico.

Encontra-se dentre nossas preocupações contribuir para desenvolver um novo modo de olhar para rochas, minerais e, finalmente, a Terra como um todo. Acreditamos que tal atitude está vinculada a conceitos e habilidades a serem adquiridas pelos alunos. Tomamos a abordagem pedagógica de Domingo \& Sequeiros (1998): isso nos revela que é difícil separar teoria e prática de laboratório pois usualmente a prática cruza com a teoria e vice versa.

Nossa estrutura inclui diferentes facetas educacionais:

1) Indo do familiar para o distante. A instrução baseia-se na idéia de que o estudante deve aprender uma idéia nova a partir de seus conceitos pessoais ( $p$. ex., o estudo da geosfera é iniciado por observações de campo e acidentes naturais).

2) Trabalhando de modo colaborativo em pequenos grupos. Os estudantes devem trabalhar juntos para responder questões que admitam o salto qualitativo de idéias e beneficiem o avanço do pensamento de todos os membros de um pequeno grupo. Em grupos de 4 ou 5 alunos, são desafiados a desenvolver tópicos que necessitam comparar e avaliar dados e evidências que conduzem, p. ex. a compreender a teoria da tectônica de placas.

3) Pesquisando uma explicação geral para um conjunto de dados. Os estudantes são postos diante de observações e questões introduzidas pela perspectiva de Tectônica de Placas e são conduzidos a alcançar uma conclusão geral coerente com os dados selecionados.

4) Entendendo que a Ciência está em permanente mudança. Os desafios postos para os alunos revelam que as explanações científicas eram diferentes há dez anos atrás e, certamente, serão diferentes nos próximos anos.

Tal estrutura gera uma seleção dos principais objetivos que se espera sejam atingidos pelos estudantes na unidade geosfera. O primeiro grupo de alvos vincula-se a idéias e conceitos:

1) Discutir a noção de acidente geológico relacionado a regiões sísmicas e vulcânicas.

2) Reconhecer os principais limites de placas e explicar os principais processos que ali ocorrem.

3) Descrever as principais características dos tipos de bordas de placas litosféricas atuais

4) Discutir a teoria da Tectônica de Placas como uma integração de duas outras explanações (deriva continental e espalhamento do assoalho oceânico).

5) Reconhecer no campo alguns registros de glaciação e explicar como eles poderiam ter sido originados. 
6) Reconhecer alguns tipos de minerais e rochas e seu respectivo ambiente tectônico de formação.

7) Compreender os processos associados à Tectônica de Placas no presente e nos últimos $200 \mathrm{Ma}$

8) Compreender algumas relações entre movimentos de placas litosféricas, suas causas e consequências à espécie humana.

9) Examinar terremotos, tsunamis e vulcões segundo uma a perspectiva dupla: como um acidente geológico e como consequência natural do movimento de placas.

O grande número de metas pode se explicado quando consideramos que a unidade Geosfera possui 29 horas (a disciplina toda possui 90h). As atividades são apresentadas no Quadro 2. Outro conjunto de metas é relacionada a habilidades que os estudantes devem possuir ao final das atividades sobre Geosfera:

10) Observar, comparar e discutir dados tectônicos básicos relacionados à teoria da Tectônica de Placas.

11) Coletar informação relevante sobre sismicidade, vulcanismo e morfologia de oceanos e continentes para defender a teoria.

12) Aplicar o raciocínio geológico para elaborar modelos e explanações científicas.

Pequeno grupo. Idéias básicas sobre classificação e seriação dos materiais terrestres.

Trabalho de campo. A rocha Moutonnée e as rochas sedimentares Permo-Carboníferas relacionadas aos depósitos glaciais de Gondwana.

Debate: Glaciação Permo-Carbonífera e deriva continental.

Leitura. Cuidado: Terremoto! Estudo sobre Afeganistão e Colômbia.

Palestra. Distribuição de zonas sísmicas modernas, origem de terremotos e terrenos falhados.

Vídeo. Por que ainda existem montanhas?

Pequeno grupo. Modelo do interior da Terra.

Video. A máquina viva (56’).

Aula de laboratório computacional. Tectônica de Placas: como funciona?

Pequeno grupo. A estrutura moderna da geosfera. Conferência. Tectônica de Placas: efeitos e implicações para o território brasileiro.

Pequeno grupo. Ambientes formadores de rochas e minerais.

Quadro 2: Seqüência de atividades desenvolvidas na unidade Geosfera.

Chart 2: Sequence of activities developed into Geosphere unit.

Tal perspectiva permite estender a abordagem à área social (muito necessária nesse caso). O valor atribuído do próximo ao distante e do familiar ao não-familiar possui papel epistemológico relevante, já que se pode trabalhar com a idéia de paisagem. Essa foi a forma encontrada para aprofundar as relações entre geografia e geologia. O ponto central é adquirir uma atitude ética diante dos processos naturais, eventos sociais e suas relações.

\section{DISCUSSÃO}

Ainda não há uma avaliação sistemática do trabalho, pois ele encontra-se em fase de implantação e caracterização de diretrizes, mas a experiência revela que o aprendizado de uma parcela dos estudantes tem sido razoável. Os resultados preliminares, porém, mostram-se satisfatórios para preparar os alunos interessados em carreiras diferentes (geologia e geografia) e eles têm mostrado capacidade para disciplinas tão distantes quanto mineralogia e geografia regional.

Isso nos conduz a sustentar a abordagem coordenada que envolva a natureza da geografia e da geologia e seus métodos de pesquisa. Uma plena sistematização, contudo, somente será atingida nos próximos anos.

No tocante ao trabalho de campo, compartilhamos da visão dominante sobre sua relevância nas geociências. Trata-se de etapa presente em todos os estágios que geram o conhecimento. Para Orion \& Hofstein (1994), trabalhos de campo devem ser planejados, antes como parte integral de um currículo que como atividade isolada. As duas disciplinas admitem dois tipos de trabalhos de campo, mediante os quais espera-se isso que o aluno vá aos poucos compreendendo a dinâmica da pesquisa científica ao exercitar certas simulações durante as atividades de campo:

1) na forma de excursões, que objetivam revelar o confronto entre o conhecimento ambiental do aluno e os diferentes estágios do conhecimento científico;

2) na forma de estudos isolados do meio, durante atividades de pesquisa dirigidas à elaboração de seminários internos da disciplina, aproveitando-se experiências anteriores, tais como as descritas por Gonçalves et al. $(1994,1998)$.

Os estudantes, durante as excursões, são conduzidos a:

1) revelar seu conhecimento ao observar e interpretar processos naturais e registros geológicos (Nummer \& Carneiro, 1998). Os primeiros passos são dados sem ajuda dos professores, de maneira inicialmente motivadora (Compiani \& Carneiro, 1993), para que eles explicitem e registrem suas próprias idéias. Esse nível de entendimento pode corresponder a uma etapa hipotética na construção do conhecimento científico (Spencer, 1997).

2) comparar suas próprias idéias com o conhecimento científico sistemático por meio de discussões com colegas e professores. Nessa etapa os alunos precisam mudar suas idéias e adotar a perspectiva científica por meio dessa mediação.

3) compreender de modo realista como a ciência realiza suas práticas e elabora teorias, explicações e hipóteses. Trata-se de passos que insistentemente superam o conhecimento por meio de reformulação, debate e complementação. Isso pode ser encontrado na ciência e praticado no ensino, como o revelam Praia (1996) e Sequeiros (1997) ao utilizar a história da ciência no ensino. 
O interesse dos alunos foi alto durante o estudo da unidade geosfera. Devemos recordar que muitos revelam pouco interesse em estudar ciências e que o entusiasmo não foi o mesmo para todos esses jovens. Acreditamos porém que tais resultados foram conseqüência tanto das estratégias didáticas adotadas, como da organização de conteúdo.

\section{CONSIDERAÇÕES FINAIS}

No trabalho didático até o momento conduzido não se atingiu ainda uma nítida integração - nem nos parece necessário atingir - dos estudos da natureza com aqueles da geografia humana (dedicada ao sistema mundo). A proposta realmente evoluiu no sentido de atingir antes uma articulação do que a integração de ambos os campos da Ciência.

Desde os primeiros passos do trabalho deu-se mais ênfase ao campo epistemológico. Há uma perspectiva de construir o conhecimento que se acha fortemente assentada na epistemologia que estruturou o conhecimento sobre o planeta. A história da ciência não é tomada em si mesma (embora em certos tópicos sejam explicitados alguns personagens relevantes para o avanço do conhecimento), mas naquilo que ela informa sobre as marcas que estruturam e organizam os estudos sobre a Terra.

Trata-se no caso de uma espécie de epistemologia aplicada para compreender o planeta. A escala de tratamento espacial e temporal dos processos é uma das noções que os estudantes não dominam e que ajuda a entender os eventos geológicos e geográficos. Isso se manifesta sobretudo em certos tópicos de estudo de fenômenos e processos que abrem canais auxiliares de investigação pelos estudantes e que favorecem todos os demais estudos promovidos no âmbito da disciplina.

As esferas sólidas do planeta são aquelas capazes de registrar da maneira mais completa os fenômenos do passado e do presente, desde que o registro tenha sido preservado; constituem portanto os mais adequados sítios de onde deve ter origem qualquer estudo de integração do ambiente terrestre. O estudo da unidade geosfera constitui, nesse âmbito, uma espécie de espinha dorsal no tratamento dos demais temas focalizados, possibilitando que o enfoque de um sistema Terra integrado seja apoiado na vertente "rochosa" dos fenômenos naturais.

\section{REFERÊNCIAS}

AMARAL, I. A. do. O conteúdo e o enfoque dos livros de geologia introdutória: estudo descritivo e analítico com base na macro-estrutura das obras atuais destinadas ao nível superior de ensino. São Paulo: Inst. Geoc., Univ. São Paulo, 1981c. 259p. (Dissertação, Mestrado em Geociências).

CARNEIRO, C.D.R.; BRITO-NEVES, B.B.de; AMARAL, I.A.do; BISTRICHI, C.A. 1994. O Atualismo como princípio metodológico em Tectônica. Bol. Geoc. Petrobrás. v. 8, n. 2/4, p. 275-293.
CARNEIRO, C.D.R.; GONÇALVES, P.W.; CUNHA, C.A.L.; NEGRÃO, O.B.M.; FIGUEIREDO, B.R.; SOUZA, M.A. de. 1998. Ciência do Sistema Terra: entendendo como o planeta funciona. In: CONGR. BRAS. GEOL., 40, Belo Horizonte, 1998. Anais... Belo Horizonte, SBG. p. 369.

CARNEIRO, C. D. R.; GONÇALVES, P. W.; NEGRÃO, O. B. M.; CUNHA, C. A. L.; SOUZA, M. A. A. de. 2000. Earth System science: a way to understand how the planet works. In: INTERN. GEOL. CONGR., 31, Rio de Janeiro, 2000. Abstracts... Rio de Janeiro: IUGS. (presented 16/08/2000, booth J23, section 26-4; keynote speaker presentation 17/ 08/2000)

COMPIANI, M.; CARNEIRO, C.D.R. 1993. Os papéis didáticos das excursões geológicas. Rev. de la Enseñanza de las Ciencias de la Tierra. v. 1, n. 2, p. 90-98.

CUELLO GIJÓN, A. 1988. La geología como area interdisciplinar. Henares, Rev. Geol., v. 2, p. 367-387.

DEAN, D. R. 1992. James Hutton and the history of geology. Ithaca: Cornell University Press. 303 p.

DOMINGO, M.; SEQUEIROS, L. 1998. La extinción de la Geologia en España: alerta roja. Rev. de la Enseñanza de las Ciencias de la Tierra. v. 6, n. 3, p. 206-210.

EARTH SCIENCE CURRICULUM PROJECT (ESCP). 1973, 1976. Investigando a Terra. v. 2. São Paulo, McGraw-Hill. $240 \mathrm{p}$.

EARTH SCIENCE CURRICULUM PROJECT (ESCP). 1975. Investigando a Terra. v. 1. São Paulo, McGraw-Hill. 435p.

FRODEMAN, R.L., 1995. Geological reasoning: Geology as an interpretive and historical science. Geol. Soc. Am. Bull., v. 107, n. 8, p. 960-968.

FRODEMAN, R.L. 1996. Envisioning the outcrop. J. Geosc. Educ., v. 44, p. 417-427.

FYFE, W.S. 1997. As ciências da Terra e a sociedade: as necessidades para o século XXI. Estudos Avançados, USP, v. 11, n. 30, p. $175-190$.

GONÇALVES, P. W. 1997. A luz invisível: o conceito de analogia na doutrina natural e moral de James Hutton. Campinas: Universidade Estadual de Campinas. 373p. (Thesis, Doctor of Philosophy).

GONÇALVES, P.W.; CARNEIRO, C.D.R.; CUNHA, C.A.L.S.; LIMA, C.V. de; LONGO, J.M.; TANAKA, M.O. 1994. Trajetória de aperfeiçoamento de uma experiência de integração de ensino e pesquisa de Geologia introdutória para alunos de Biologia. In: SIMP. DE LA ENSEÑANZA DE GEOLOGÍA, Córdoba, 1994. Anais... Córdoba: AEPECT. Rev. de la Enseñanza de las Ciencias de la Tierra vol. 3, n. Extra, Septiembre, p. 40-43.

GONÇALVES, P. W.; CARNEIRO, C. D. R.; NEGRÃO, O. B. M.; CUNHA, C. A. L. 2000. Ciência do Sistema Terra e o entendimento da "máquina" planetária em que vivemos. ENCONTRO "PERSPECTIVAS DO ENSINO DE BIOLOGIA", 7, São Paulo, 2000. Coletânea... São Paulo: International Organization for Science and Teaching Education. p. 246-248. (Contrib. 2202).

GOULD, S. J. Is uniformitarianism necessary? American Journal of Sciences, New Have, Conecticut, 1965, vol. 263, p. 223228 .

HOLMES, A. \& HOLMES, D.L. Principles of physical geology. 3. ed. rev. London: Thomas Nelson and Sons, 1979. 730p. (primeira edição HOLMES 1944).

HOLMES, A. Principles of physical geology. London: Thomas Nelson and Sons, 1965. 1288p.

HUTTON, J. 1899. Theory of the earth, with proofs and illustrations. Edited by Sir Archibald Geikie. London, Geological Society. 278p.+ index 13pp.

JONES, J. 1986. James Hutton. In: DAICHES, D.; JONES, P.; JONES, J. eds. A hotbed of genius: the Scottish enlightenment 1730-1790. Edinburgh University Press. Edinburgh. (Tradução para o Português, apresentação e notas suplementares por Pedro Wagner Gonçalves). 
KING, C. 1990. Earth systems: new interdisciplinarity major looks a problems facing the planet. The Stanford Earth Scientist, p. 8-12.

LEINZ V. \& AMARAL S.E. do, 1989. Geologia geral. 11 ed. São Paulo: Cia. Ed. Nacional. (primeira edição de 1962)

LOON, A.J. van 1999. The meaning of "abrupteness in the geological past. Earth Sci. Rev. v. 45, p. 209-214.

MACKENZIE, F. T. \& MACKENZIE, J. A. 1995. Our changing planet. An introduction to earth system science and global environmental change. Englewood Cliffs: Prentice Hall. $387 \mathrm{p}$

NUMMER, A.R.; CARNEIRO, C.D.R. 1998. The comprehension of space by the study of tectonic structures on different observation scales. In: INTERN. CONF. ON GEOSC. EDUC., 2, Hilo, Hawaii, 1997. Conference Proceedings... Ohio: The Ohio State University. p. 160

POTAPOVA, M.S. 1968. Geology as an historical science of nature. In: Interaction of the science in the study of the earth. Moscow: Progress. p. 117-126.

PRAIA, J.F. 1996. Epistemologia e historia de la ciencia: contribuciones a la planificación didáctica. La deriva continental. Rev. de la Enseñanza de las Ciencias de la Tierra, v. 4, n. 1, p. 30-37.

SEQUEIROS, L. et al. 1997. James Hutton y su teoría de la Tierra (1795): consideraciones para secundaria. Rev. de la Enseñanza de las Ciencias de la Tierra, v. 5, n. 1, p. 11-20.

SIMPSON, G.G. 1970. La Ciencia histórica. In: ALBRITTON JR., C.C. (Org.). Filosofía de la geología. México: Continental. p. 39-94.

SPENCER, Patrick K. 1997. The method of multiple working hypotheses in undergraduate education with an example of its application and misapplication. J. Geosc. Educ., v. 45, n. 2, p. 123-128, Mar. 1997.

TARBUCK, E. J. \& LUTGENS, F. K. 1996. Earth. An introduction to physical geology. Upper Saddle River: Prentice Hall. 605p. 